\title{
Predictors of Long Covid 19 Syndrome
}

\author{
Ahmed F. Mady ${ }^{1}$, Rash A. Abdelfattah ${ }^{1}$, Fatma M.M. Kamel*2, \\ Al Shaimaa Mamdouh Abdel Naiem ${ }^{3}$, Wael M. AbdelGhany ${ }^{4}$, Ali Omar Abdelaziz ${ }^{1}$ \\ Departments of ${ }^{1}$ Chest Diseases, ${ }^{2}$ Internal Medicine, ${ }^{3}$ Rhumatological and Rehabilitation and \\ Tropical Medicine ${ }^{4}$, Faculty of Medicine, Minya University, Egypt \\ *Corresponding author: Fatma Mohamed Mohamed Kamel, Mobile: (+20)1007407599, E-mail: fatma.kamel@mu.edu.eg
}

\begin{abstract}
Background: Symptoms of covid persist in most cases with development of a multisystem syndrome called long covid syndrome.

Objective: The aim of the work was to evaluate symptoms that persist after the acute stage of the disease in a cohort of patients with confirmed or suspected COVID 19 and to define the predictors for long COVID syndrome.

Patients and method: This retrospective study involved 164 patients with previously confirmed or highly suspected COVID 19 and still attending to the post covid outpatient clinic in El-Minia University Chest Hospital complaining from persistence of symptoms or for regular follow up. Their data was obtained from their previous medical reports.

Results: Post Covid 19 symptoms were found in about $86 \%$ of the studied patients with $42.7 \%$ reported neuropsychiatric symptoms and $26.8 \%$ reported respiratory symptoms. The most common reported symptoms in nonsevere cases were the anxiety disorders (18.9\%), followed by chronic fatigue and neuropathy (15.2\%), while chronic dyspnea in $9.8 \%$ mostly in severe cases, while vertigo and headache in $9.1 \%$, musculoskeletal symptoms in $6.1 \%$ and skin lesions in $3.7 \%$.
\end{abstract}

Conclusion: It could be concluded that persistence of symptoms is very common after acute Covid 19 infection. Chronic dyspnea was reported more frequently in severe cases while anxiety reported mostly by patients with mild disease.

Keywords: Long covid syndrome, Post covid syndrome, Persistent symptoms, chronic fatigue syndrome.

\section{INTRODUCTION}

A novel coronavirus (nCoV) disease (COVID-19) has been defined as a pandemic health problem caused by a newly discovered SARS COV-2 virus. Post covid19 ("long covid") is a multisystem syndrome, occurring even after a mild acute illness. The patients remain suffering from multiple neuropsychiatric and respiratory symptoms as chronic dyspnea 'lung burn', tachycardia and loss of smell or taste accompanied by chronic fatigue - but not always ${ }^{(\mathbf{1})}$. The symptoms may be constantly persistent or fluctuate. It may take days till feeling well but may recur sometimes following exertion and sometimes for no apparent reason ${ }^{(2)}$.

Greenhalgh et al. ${ }^{(3)}$ define the post-acute covid19 symptoms that extending beyond three weeks from the onset of first symptoms and chronic covid-19 which extend beyond 12 weeks.

The aim of the present study was to evaluate symptoms that persist after the acute stage of the disease in a cohort of patients with confirmed or suspected COVID 19 and to define the predictors for long COVID syndrome.

\section{PATIENTS AND METHODS}

For the purpose of this study, we used the definition of post COVID 19 syndrome as symptoms that persist for beyond 3 months from the start of the disease.

This retrospective study included a total of 164 patients with previously confirmed or highly suspected COVID 19 attending at the Post Covid Outpatient complaining of persistence of symptoms or for regular follow up.

Their data was obtained from their previous medical reports. Demographic data, comorbidities, the initial presenting symptoms, and laboratory finding were recorded.

The severity of the cases was defined based on the criteria established by China's National Health Commission (4): 1- Mild: minor symptoms only, without evidence of pneumonia by chest X-ray. 2Moderate: Fever and respiratory symptoms are present, and there is evidence for pneumonia by chest X-ray, (both groups classified also as non-severe cases). 3Severe: Defined by any of the following conditions. 1) Dyspnea, respiratory rate $\geq 30 / \mathrm{min}, 2$ ) resting hypoxia $\mathrm{SaO} 2 \leq 93 \%$, 3) $\mathrm{PaO} 2 / \mathrm{FiO} 2 \leq 300 \mathrm{mmHg}$. 4. Critical: the presence of any of the following conditions. 1) Respiratory failure, require mechanical ventilation, 2) shock, 3) other acute organ failure. (Both groups classified also as a severe cases).

\section{Ethical consent:}

An approval of the study was obtained from Minya University Academic and Ethical Committee. Every patient signed an informed written consent for acceptance of the operation. This work has been carried out in accordance with The Code of Ethics of the World Medical Association (Declaration of Helsinki) for studies involving humans.

\section{Clinic, El-Minia University Chest Hospital,}




\section{Statistical analysis}

The analysis of the data was carried out using the IBM SPSS 20.0 statistical package software. Data were expressed as mean, standard deviation (SD), minimum and maximum of range for quantitative parametric measures and median (range) for non-parametric data, in addition to both number and percentage for categorized data. To assess potential risk factors for the occurrence of post COVID-19 symptoms, a forwardstepwise binary logistic regression analysis was performed. For all analyses, a P value less than 0.05 was considered statistically significant.

\section{RESULTS}

Table (1): after revising 164 patients with post covid symptoms 90 male and 74 female with different age groups from 17 to 82 years, with $21 \%$ with hypertension, 20\% with DM, 7\% with IHD and 5\% with CKD and bronchial asthma. From their medical reports, the patients were classified according to disease severity into mild $(50 \%)$, moderate $(37 \%)$, severe $(8 \%)$ and critical (5\%). The patients were also classified according to the initial presenting symptom into dry cough (28.7\%), anosmia (25.6\%), dyspnea (18.3\%), GIT symptoms (17.1\%) and fever (10.4\%).

Table (1): Sociodemographic and clinical data of studied patients:

\begin{tabular}{|l|l|}
\hline \multicolumn{2}{|l|}{ Total (N=164) } \\
\hline Age (years)- Median (Range) & $50(17-82)$ \\
\hline Sex & $74(45.1 \%)$ \\
\hline Female & $90(54.9 \%)$ \\
\hline Male & $47(28.7 \%)$ \\
\hline Comorbidities & $35(21.3 \%)$ \\
\hline Smoking & $33(20.1 \%)$ \\
\hline Hypertension & $8(4.9 \%)$ \\
\hline Diabetes Mellitus & $8(4.9 \%)$ \\
\hline Chronic Kidney Disease & $12(7.3 \%)$ \\
\hline Bronchial Asthma & $10(6.1 \%)$ \\
\hline Ischemic Heart Disease & $74(45.1 \%)$ \\
\hline Cancer & $82(50.0 \%)$ \\
\hline Female & $61(37.2 \%)$ \\
\hline Case classification & $13(8 \%)$ \\
\hline Mild & $8(5 \%)$ \\
\hline Moderate & $30(18.3 \%)$ \\
\hline Severe & $47(28.7 \%)$ \\
\hline Critical & $42(25.6 \%)$ \\
\hline Initial presenting symptom & $28(17.1 \%)$ \\
\hline Dyspnea & $17(10.4 \%)$ \\
\hline Dry cough & \\
\hline Anosmia & \\
\hline GIT symptoms & \\
\hline Fever &
\end{tabular}

Table (2): it shows the median of variable hematological and biochemical laboratory investigations including: CBC, Neutrophil-Lymphocyte Ratio (NLR), Neutrophil to lymphocyte ratio (NLR), liver enzymes, renal function, serum LDH, ferritin, CRP and D-dimer.

Table (2): Laboratory findings among the studied group:

\begin{tabular}{|c|c|}
\hline & Total $(\mathrm{N}=164)$ \\
\hline $\begin{array}{l}\text { Hemoglobin level (g/dl) } \\
\text { Mean } \pm \text { SD }\end{array}$ & $12.1 \pm 2$ \\
\hline $\begin{array}{l}\text { Plateletes (x10³/cumm) } \\
\text { Median ( }\end{array}$ & 231 \\
\hline $\begin{array}{l}\text { WBCs (x10³/cumm) } \\
\text { Median }\end{array}$ & 6.8 \\
\hline $\begin{array}{l}\text { Neutrophil \% } \\
\text { Mean } \pm \text { SD }\end{array}$ & $62.7 \pm 3.4$ \\
\hline $\begin{array}{l}\text { Neutrophil count (/cumm) } \\
\text { Median }\end{array}$ & 4160 \\
\hline $\begin{array}{l}\text { Monocytes \% } \\
\text { Median }\end{array}$ & 5 \\
\hline $\begin{array}{l}\text { Monocytes count (/cumm) } \\
\text { Median }\end{array}$ & 325 \\
\hline $\begin{array}{l}\text { Lymphocytes \% } \\
\text { Median (Range) }\end{array}$ & 23 \\
\hline $\begin{array}{l}\text { Lymphocytes count(/cumm) } \\
\text { Median }\end{array}$ & 1615 \\
\hline NLR- Median & 2.6 \\
\hline LMR- Median & 4.9 \\
\hline $\begin{array}{l}\text { ALT (U/L) } \\
\text { Mean } \pm \text { SD }\end{array}$ & 327 \\
\hline $\begin{array}{l}\text { AST }(\text { U/L) } \\
\text { Mean } \pm \text { SD }\end{array}$ & $31.3 \pm 20.6$ \\
\hline $\begin{array}{l}\text { Urea }(\mathbf{m g} / \mathrm{dl}) \\
\text { Mean } \pm \text { SD }\end{array}$ & $46 \pm .7$ \\
\hline $\begin{array}{l}\text { Creatinine (mg/dl) } \\
\text { Mean } \pm \text { SD }\end{array}$ & $1.5 \pm 0.08$ \\
\hline $\begin{array}{l}\text { CRP }(\mathbf{m g} / \mathbf{l}) \\
\text { Median }\end{array}$ & 17 \\
\hline $\begin{array}{l}\text { LDH (U/L) } \\
\text { Median }\end{array}$ & 350 \\
\hline $\begin{array}{l}\text { Ferritin }(\mathbf{n g} / \mathbf{m l}) \\
\text { Median }\end{array}$ & 253.5 \\
\hline $\begin{array}{l}\text { D-dimer (mg/l) } \\
\text { Median }\end{array}$ & 0.5 \\
\hline
\end{tabular}

WBCS $=$ white blood cells, NLR= neutrophil lymphocytes ratio, $\mathrm{LMR}=$ lymphocytes monocytes ratio, $\mathrm{ALT}=$ alanine transaminase, $\mathrm{AST}=$ aspartate transaminase, $\mathrm{CRP}=\mathrm{C}$-reactive protein, $\mathrm{LDH}=$ lactate dehydrogenase.

Table (3); post Covid 19 symptoms were reported in about $79 \%$ of the studied patients. About $42.7 \%$ of the studied cohort reported neuropsychiatric symptoms and $26.8 \%$ of the patients reported respiratory symptoms with predilection of anxiety in non-severe cases ( $p$ value 0.015) and chronic dyspnea in severe cases ( $\mathrm{p}$ value $\mathbf{0 . 0 0 1}$ ). 
Table (3): Prevalence post covid symptoms in the studied patients with body systems affection:

\begin{tabular}{|c|c|c|c|c|}
\hline & Total & Non-severe $(\mathrm{N}=143)$ & Severe $(\mathrm{N}=21)$ & $P$ value \\
\hline \multicolumn{5}{|c|}{ Post-COVID fatigue and neuropathy } \\
\hline Yes & $25(15.2 \%)$ & $24(16.8 \%)$ & $1(4.8 \%)$ & \multirow{2}{*}{0.204} \\
\hline No & & $119(83.2 \%)$ & $20(95.2 \%)$ & \\
\hline \multicolumn{5}{|c|}{ Vertigo and headache } \\
\hline Yes & $15(9.1 \%)$ & $15(10.5 \%)$ & $0(0.0 \%)$ & \multirow{2}{*}{0.221} \\
\hline No & & $128(89.5 \%)$ & $21(100.0 \%)$ & \\
\hline \multicolumn{5}{|l|}{ Flaring of asthma } \\
\hline Yes & $14(8.5 \%)$ & $13(9.1 \%)$ & $1(4.8 \%)$ & \multirow{2}{*}{$>0.99$} \\
\hline No & & $130(90.9 \%)$ & $20(95.2 \%)$ & \\
\hline \multicolumn{5}{|l|}{ Anxiety symptoms } \\
\hline Yes & $31(18.9 \%)$ & $31(21.7 \%)$ & $0(0.0 \%)$ & \multirow{2}{*}{$0.015^{*}$} \\
\hline No & & $112(78.3 \%)$ & $21(100.0 \%)$ & \\
\hline \multicolumn{5}{|l|}{ Arthralgia } \\
\hline Yes & $10(6.1 \%)$ & $10(7.0 \%)$ & $0(0.0 \%)$ & \multirow{2}{*}{0.364} \\
\hline No & & $133(93.0 \%)$ & $21(100.0 \%)$ & \\
\hline \multicolumn{5}{|l|}{ Skin lesions } \\
\hline Yes & $6(3.7 \%)$ & $5(3.5 \%)$ & $1(4.8 \%)$ & \multirow{2}{*}{0.567} \\
\hline No & & $138(96.5 \%)$ & $20(95.2 \%)$ & \\
\hline \multicolumn{5}{|l|}{ Dry cough } \\
\hline Yes & $14(8.5 \%)$ & $13(9.1 \%)$ & $1(4.8 \%)$ & \multirow{2}{*}{$>0.99$} \\
\hline No & & $130(90.9 \%)$ & $20(95.2 \%)$ & \\
\hline \multicolumn{5}{|l|}{ Chronic dyspnea } \\
\hline Yes & $16(9.8 \%)$ & $9(6.3 \%)$ & $7(33.3 \%)$ & 0.001* \\
\hline No & & $134(93.7 \%)$ & $14(66.7 \%)$ & \\
\hline \multicolumn{5}{|l|}{ System affected } \\
\hline Respiratory & & & $44(26.8 \%)$ & \\
\hline CNS & & & $70(42.7 \%)$ & \\
\hline Skin & & & $6(3.7 \%)$ & \\
\hline Musculoskeletal & & & $10(6.1 \%)$ & \\
\hline No & & & $34(20.7 \%)$ & \\
\hline
\end{tabular}

Table (4); by applying univariate binary logistic regression analysis, it was found that smoking and disease severity are significantly associated with chronic dyspnea while chronic fatigue associated with DM.

Table (4): Univariate logistic regression analyses for post COVID-19.

\begin{tabular}{|c|c|c|c|}
\hline Dependent variable & Variable & Crude OR (95\% CI) & $p$ value \\
\hline \multirow{9}{*}{ Chronic dyspnea } & Age (years) & $1.04(1-1.09)$ & $0.04 *$ \\
\hline & Smoking & $3.72(1.3-10.68)$ & $0.015 *$ \\
\hline & WBCs (x10 $/$ cumm) & $1.13(1.03-1.24)$ & 0.011* \\
\hline & Neutrophil (/cumm) & $1.07(1.02-1.11)$ & $0.005 *$ \\
\hline & Neutrophil count (/cumm) & $1(1-1)$ & 0.004* \\
\hline & NLR & $1.18(1.05-1.32)$ & $0.005 *$ \\
\hline & LDH (U/L) & $1(1-1)$ & $0.025 *$ \\
\hline & Ferritin (ng/ml) & $1(1-1)$ & 0.006* \\
\hline & Severity & $7.44(2.4-23.06)$ & 0.001* \\
\hline Fatigue & DM & $6.45(2.58-16.12)$ & $<0.001 *$ \\
\hline Vertigo and headache & CRP (mg/l) & $1.01(1-1.02)$ & 0.009* \\
\hline \multirow{6}{*}{ Anxiety } & Age (years) & $1(0.9-1)$ & 0.034* \\
\hline & BA & $4.8(1.1-20.3)$ & 0.034* \\
\hline & WBCs $\left(x^{10} /\right.$ cumm $)$ & $0.9(0.8-1)$ & 0.02* \\
\hline & Neutrophil count (/cumm) & $1(1-1)$ & 0.041* \\
\hline & Monocytes count (/cumm) & $1(1-1)$ & 0.016* \\
\hline & LMR & $1.1(1-1.1)$ & 0.019* \\
\hline \multirow[t]{2}{*}{ Skin lesions } & IHD (mg/dL) & $7.4(1.21-45.41)$ & 0.031* \\
\hline & Monocytes count (/cumm) & $1(1-1.01)$ & 0.011* \\
\hline \multirow[t]{3}{*}{ Dry cough } & Age (years) & $1.05(1-1.09)$ & $0.045^{*}$ \\
\hline & HTN (g/dl) & $3.13(1.01-9.72)$ & 0.049* \\
\hline & IHD (mg/dL) & $4.27(1.01-18.1)$ & $0.049 *$ \\
\hline
\end{tabular}


Table (5); multivariate analysis found that anxiety symptoms clearly associated with bronchial asthma, while ischemic heart diseases leads to dry cough and chronic dyspnea was highly associated with smoking and disease severity.

Table (5): Multivariate logistic regression analyses for post COVID-19 symptoms:

\begin{tabular}{|l|l|c|c|}
\hline \multirow{2}{*}{ Dependent variable } & \multicolumn{1}{|c|}{ Variable } & Crude OR (95\% CI) & P value \\
\cline { 2 - 4 } & Age (years) & $0.97(0.94-1)$ & $\mathbf{0 . 0 3 7} *$ \\
\cline { 2 - 4 } & BA & $5.67(1.21-26.55)$ & $\mathbf{0 . 0 2 8}^{*}$ \\
\hline Drin lesions & Monocytes count & $1(1-1.01)$ & $\mathbf{0 . 0 2} *$ \\
\hline \multirow{3}{*}{ Chronic dyspnea } & IHD & $4.27(1.01-18.10)$ & $\mathbf{0 . 0 4 9}$ \\
& Smoking & $3.73(1.17-11.86)$ & $\mathbf{0 . 0 2 6}^{*}$ \\
\cline { 2 - 4 } & Ferritin & $1(1-1)$ & $\mathbf{0 . 0 1}^{*}$ \\
\cline { 2 - 4 } & Disease severity & $5.8(1.76-19.12)$ & $\mathbf{0 . 0 0 4}^{*}$ \\
\hline
\end{tabular}

\section{DISCUSSION}

Persistence of symptoms for variable period of time after acute covid-19 infection has been reported in several studies. Greenhalgh et $\boldsymbol{a l}^{\left({ }^{(3)}\right.}$ defined post-acute covid-19 as extending beyond three weeks from the onset of first symptoms and chronic covid-19 as extending beyond 12 weeks. Persistence of symptoms after acute covid-19 is not limited to patients with severe infection but studies also reported that even those patients with mild disease may experience long term symptoms. The most common reported symptoms were cough, fatigue, dyspnea, chest pain, fever, neurocognitive dysfunction, headache and many other symptoms (5, 6). The persistence of symptoms following the acute stage of the diseases is not specific for COVID-19. Many other infectious diseases can result in symptoms that last for prolonged time ${ }^{(7,8)}$.

In the present study, post Covid 19 symptoms presented mainly with neuropsychiatric symptoms then respiratory symptoms. The most common reported symptoms in our cohort of patients were the anxiety disorders (18.9\%) which include tachycardia, sweating with occasional panic attacks in previously normal individuals, followed by chronic fatigue and neuropathy (15.2\%) (Tingling, numbness and tremors in the extremities). Chronic dyspnea was present in $9.8 \%$ and it was associated with persistent abnormal radiological finding, vertigo and headache was present in $9.1 \%$. Arthralgia and myalgia were present in $6.1 \%$. A skin lesion distributed mostly on limbs and back was present in 3.7\%.

Our results are comparable with those reported by Carfî et al. ${ }^{(9)}$ in a cohort of hospitalized COVID-19 patients; they reported that $87 \%$ of the patients reported one or more symptoms for two months after the onset of initial symptoms. Similarly, Goertz et al. ${ }^{(10)}$ in a survey study of patients with suspected or confirmed COVID-19 found that the majority of the patients still experience variable symptoms at 3 months after the onset of the disease.

Garrigues et al. ${ }^{(11)}$ evaluated 120 hospitalized patients with COVID-19, follow up of those patients after 100 day of their discharge revealed that fatigue was present in $55 \%$, dyspnea was reported by $42 \%$ and loss of memory were complained by $34 \%$ of the studied cohort. In another study carried out by Zhao et al. ${ }^{(12)}$, the most common symptoms reported by patients at 3 month follow up were GI symptoms (30.91\%); headache (18.18\%); fatigue
(16.36\%); dyspnea in $14.55 \%$, cough and sputum in $1.81 \%$; disturbance in taste sensation in $4 \%$.

Savarraj et al. ${ }^{(\mathbf{1 3})}$ found that at 3 month follow up $71 \%$ of the patients complaining of neurological symptoms with pain was the most reported symptoms $(64 \%)$ followed by fatigue (42\%) and cognitive symptoms (12\%).

At present the mechanisms behind the persistence of symptoms in post-acute COVID-19 are still uncertain. Many possibilities could be responsible for example, persistent viraemia and autoimmune reaction. Inflammatory reaction could also be implicated.

In this study and after applying univariate binary logistic regression analysis to assess the possible risk factors for post covid symptoms, it was found that smoking and disease severity are significantly associated with chronic dyspnea with odds ratio $3.72,7.44$ respectively and $\mathrm{p}$ value $0.015,0.001$ with significant association also with age, WBCs, neutrophil count, and percentage, NLR, LDH and serum ferritin with odds ratio 1 for each of them.

Previous studies had shown conflicting results regarding the association between the severity of the diseases and development of chronic post-COVID19 symptoms. While Carvalho-Schneider et al. ${ }^{(\mathbf{1 4})}$ showed an association between the severity of the diseases and the development of chronic symptoms some other studies found no significant association ${ }^{(15,11)}$. In our study we found that disease severity was significantly associated with persistence of dyspnea at 3 month follow up.

Some studies have evaluated the risk factors for the persistence of symptoms in post-acute COVID-19. The presence of dyspnea in the acute phase of the disease and having Asthma or chronic lung disease was associated with the risk of having chronic dyspnea in two studies ${ }^{(14,16)}$.

In the current study we found significant association between presences of comorbidities and post COVID-19 symptoms. Diabetes was significantly associated with fatigue with odds ratio 6.45 and p value < 0.001 , bronchial asthma with anxiety with 4.8 odds ratio and $0.034 \mathrm{p}$ value. Ischemic heart disease and hypertension were significantly associated with the persistence of dry cough $(4.27,3.13)$ odds ratio respectively and $0.049 \mathrm{p}$ value. These findings are in accordance with previous study ${ }^{(17)}$.

Multivariate logistic regression analyses showed that young age and bronchial asthma were predictors for the occurrence of anxiety disorder $(0.97,5.67)$ odds ratio and $(0.037,0.028) \mathrm{p}$ value. Smoking, elevated serum 
ferritin and disease severity are predictors for the persistence of dyspnea with $(3.73,1,5.8)$ odds ratio respectively and $\mathrm{p}$ value $(0.026,0.01,0.004)$. IHD was predictors of cough 4.27 odds ratio and $0.049 \mathrm{p}$ value and elevated monocytes count was a predictor for the presence of skin lesion.

Our results are in accordance with some other studies De Lorenzo et al. ${ }^{(15)}$, Halpin et al. ${ }^{(18)}$, Mazza et al. ${ }^{\left({ }^{(9)}\right)}$, Taquet et al. ${ }^{(20)}$ they found that ;younger age, being of female gender, or previous diagnosis of a psychiatric disorder are being risk factors the persistent psychiatric symptoms.

\section{CONCLUSION}

It could be concluded that persistence of symptoms is common after the acute phase of COVID 19 infection. Post covid syndrome occurs regardless of the disease severity. Neuropsychiatric symptoms were the commonest reported symptoms. Anxiety disorder was reported more in patients with mild disease. The young age and presence of bronchial asthma were predictors for the occurrence of anxiety. Severity of the disease, serum ferritin level and smoking were predictors for post COVID dyspnea.

\section{Financial support and sponsorship: Nil.}

\section{Conflict of interest: Nil.}

\section{REFERENCES}

1. Geddes L (2020): Why strange and debilitating coronavirus symptoms can last for months. https://www.newscientist.com/article/mg24632881-400why-strange-and-debilitating-coronavirus-symptomscan-last-for-months/

2. Chen H, Sun L, Du Z et al. (2020): A cross-sectional study of mental health status and self-psychological adjustment in nurses who supported Wuhan for fighting against the COVID-19. Journal of Clinical Nursing, 29(21-22):4161-70.

3. Greenhalgh T, Knight M, Buxton $M$ et al. (2020): Management of post-acute covid-19 in primary care. https://pubmed.ncbi.nlm.nih.gov/32784198/

4. Wei F (2020): Diagnosis and Treatment Protocol for Novel Coronavirus Pneumonia (Trial Version 7). Chin Med J (Engl), 133(9):1087-1095.

5. McCorkell L, Assaf G, Davis H et al. (202): Patient-Led Research for COVID-19: Embedding Patients in the Long COVID Narrative. Pain Rep., 6(1): 913-18.

6. Dasgupta A, Kalhan A, Kalra S (2020): Long term complications and rehabilitation of COVID-19 patients. J Pak Med Assoc., 70(5): 131-5.

7. Lam M, Wing Y, Yu M et al. (2009): Mental morbidities and chronic fatigue in severe acute respiratory syndrome survivors: long-term follow-up. Archives of Internal Medicine, 169(22):2142-7.

8. Metlay J, Fine M, Schulz R et al. (1997): Measuring symptomatic and functional recovery in patients with community-acquired pneumonia. Journal of General Internal Medicine, 12(7):423-30.

9. Carfî A, Bernabei R, FGemelli L (2020): Against COVID-19 Post-Acute Care Study Group. Persistent symptoms in patients after acute COVID-19. JAMA., 69: 993-8.

10. Goërtz Y, Van Herck M, Delbressine J et al. (2020): Persistent symptoms 3 months after a SARS-CoV-2 infection: the post-COVID-19 syndrome? ERJ Open Res., 6(4):00542-2020.

11. Garrigues E, Janvier P, Kherabi Y et al. (2020): Postdischarge persistent symptoms and health-related quality of life after hospitalization for COVID-19. Journal of Infection, 81(6): 4-6.

12.Zhao H, Xie Y, Wang C (2020): Recommendations for respiratory rehabilitation in adults with coronavirus disease 2019. Chinese Medical Journal, 133(13):1595.

13.Savarraj J, Burkett A, Hinds S et al. (2020): Threemonth outcomes in hospitalized COVID-19 patients. medRxiv, 20: 1-7.

14. Carvalho-Schneider C, Laurent $E$, Lemaignen A et al. (2021): Follow-up of adults with noncritical COVID-19 two months after symptom onset. Clinical Microbiology and Infection, 27(2):258-63.

15. De Lorenzo R, Conte C, Lanzani C et al. (2020): Residual clinical damage after COVID-19: A retrospective and prospective observational cohort study. PLoS One, 15(10): 239-243.

16. Cellai M, O'Keefe J (2020): Characterization of prolonged COVID-19 symptoms in an outpatient telemedicine clinic. Open forum infectious diseases. Open Forum Infectious Diseases, 4(10): 420-424.

17.Stavem K, Ghanima W, Olsen M et al. (2021): Persistent symptoms 1.5-6 months after COVID-19 in non-hospitalised subjects: a population-based cohort study. Thorax, 76(4):405-7.

18. Halpin S, McIvor C, Whyatt G et al. (2021): Postdischarge symptoms and rehabilitation needs in survivors of COVID-19 infection: A cross-sectional evaluation. Journal of Medical Virology, 93(2):1013-22.

19. Mazza M, De Lorenzo R, Conte C et al. (2020): Anxiety and depression in COVID-19 survivors: Role of inflammatory and clinical predictors. Brain, Behavior, and Immunity, 89: 594-600.

20. Taquet $M$, Luciano S, Geddes $J$ et al. (2021): Bidirectional associations between COVID-19 and psychiatric disorder: retrospective cohort studies of 62 354 COVID-19 cases in the USA. Lancet Psychiatry, 8(2):130-140. 